\title{
Argumentos racionales y bíblicos sobre la pena de muerte en la patrística
}

\author{
Hernán Giudice \\ FACULTAD DE TEOLOGÍA \\ PONTIFICIA UNIVERSIDAD CATÓLICA ARGENTINA
}

La consideración de los escritores patrísticos sobre la pena de muerte varía desde la simple aceptación de la misma hasta una prohibición total de la pena capital, pasando por posiciones intermedias. Tanto antes de Constantino - cuando la pena de muerte se aplicó a muchos cristianos durante las persecuciones- como bajo el cambio que produjo su llegada al poder, no siempre la pena capital se pensó de la misma manera. Los autores cristianos tratan de esta cuestión y temas conexos, como el de la participación en el ejército, con argumentos racionales y con argumentos tomados de la Sagrada Escritura.

\section{Argumentos racionales}

Clemente alejandrino es el primer autor cristiano que justifica el sistema penal con argumentos racionales. Presenta a Moisés como el mejor legislador y muestra los castigos de la Ley mosaica como medios que orientan a la virtud. Hace el elogio de la Ley en implícita alusión a Marción, quien rechazaba al Dios Creador, Justo y Legislador: «Que nadie insulte a la ley como inepta y malvada solo a causa de los castigos que inflije». Explica el sistema penal desde la imagen médica: un delicuente es como una extremidad infectada que contamina el cuerpo social. Concibe el fin primario de la ley penal como reforma del delincuente, sin embargo, cuando se piensa que el mismo se vuelve irreformable, justifica la pena de muerte como liberación de futuros males para la sociedad ${ }^{1}$. Al tratar sobre los premios

1 Clemente, Stromata 1, 27, 171: "Que nadie insulte a la ley como inepta y malvada solo a causa de los castigos que inflige. [...] Por la salud del cuerpo soportamos hacernos amputar y cauterizar, y aquel que suministra estos remedios es llamado médico, 
y castigos en la pedagogía del Logos relaciona la terapia de la mutilación con la moral expresándose así: «La reprensión es semejante a una operación quirúrgica realizada en las pasiones del alma. Las pasiones son la úlcera de la verdad y deben eliminarse dividiéndolas por la amputación» ${ }^{2}$. Resulta interesante destacar que, ya antes de Clemente, la equiparación de la administración de justicia con la medicina se remonta a Platón, el cual considera al delincuente como un enfermo incurable que amenaza al cuerpo social $^{3}$. Esta teoría hace escuela y entra en el medioevo.

Por otra parte hay autores apologistas, que aún sin hablar de la ilegitimidad de la pena capital, dicen que los cristianos se hacen culpables cuando miran una ejecución aunque fuese decretada por la ley ${ }^{4}$. Cipriano con ironía dice: «Al homicidio se lo considera un crimen cuando se comete privadamente, más se lo llama virtud cuando se ejecuta en nombre del Estado» ${ }^{5}$. Los autores africanos anteriores a Constantino se muestran partidarios de la no-violencia y presentan la objeción de conciencia para participar en el ejército. Ellos consideran al cristiano como miles Christi y la vida cristiana como la única milicia válida.

Contra la pena de muerte, siendo severo con los soldados que cumplen la orden de matar y con los jueces que aplican la pena capital, dice la Traditio Apostolica 16:

«El soldado subalterno a nadie matará y, en caso de recibir la orden, no la ejecutará ni prestará juramento. Si así no lo hiciera, será rechazado. El que tiene el poder de la espada, y también el magistrado que lleva la púrpura, lo dejarán o serán rechazados. El catecúmeno y el fiel que pretendan hacerse soldados, serán rechazados, pues han menospreciado a Dios».

salvador; él amputa algunas partes del cuerpo para que no se enfermen las partes sanas; no es por rencor o maldad hacia el paciente sino según la razón del arte que le sugiere y nadie, por lo tanto, acusaría de maldad al médico por su arte. [...] Cuando [la ley] ve a alguien de tal modo que parezca incurable, viéndolo ir por el camino de la extrema injusticia, entonces se preocupa de los otros para que no vayan a la perdición por obra de aquel, y como cortando una parte del cuerpo entero lo manda a la muerte".

2 Clemente, Pedagogo 1, 8, 64, 4.

3 Platón, «Las Leyes IX 854 E» en Gorgias 478-480.

4 Atenágoras, Legatio 35; Minucio Félix, Octavio 30, 6.

5 Cipriano, Ad Donatum 6. 
Este testimonio de la disciplina de la Iglesia primitiva, aun cuando no explica los motivos de fe que van contra la pena muerte, apunta con sus disposiciones a eliminar situaciones de vida que desdigan de la vida cristiana. El que tenga el poder de la espada o el magistrado si no renuncia se lo considera como no dispuesto a conformar su conducta con el Evangelio y por esa razón se lo aleja de la instrucción prebautismal.

En esta misma línea Tertuliano tiene una postura muy clara cuando dice que si alguien quiere servir a Dios en los puestos de poder como lo hicieron el patriarca José en Egipto y el profeta Daniel en Babilonia «no debe juzgar sobre la cabeza de nadie» ${ }^{6}$.

$\mathrm{El}$ autor más interesante con su postura contraria a la pena de muerte es el africano Lactancio. Vivió al final de las persecuciones y a inicios de la libertad de culto. Es estudiado como el mejor teórico de la no-violencia ${ }^{7}$. Rechaza la pena de muerte de modo absoluto. En temas de moral trata sobre los placeres de los sentidos, especialmente de la vista, y de modo particular sobre la participación en los espectáculos. Reconoce en los filósofos la presentación correcta de este placer, pero a su vez los critica por no haber rechazado los espectáculos donde se mata a hombres, aún cuando se trate de condenados justamente ${ }^{8}$. Habla contra la pena de muerte en Divinae institutiones 6, 20, 15-17:

«Los que se esfuerzan por seguir el camino de la justicia no deben asistir ni participar en estos crímenes públicos y es que, cuando Dios nos prohíbe matar, no sólo nos prohíbe hacer estragos - cosa que no está permitida ni siquiera en las leyes públicas-, sino que nos aconseja

6 Tertuliano, De idolatria 17 . En De spectaculis 19 se refiere a los espectadores como cómplices de los muertes en el anfiteatro. Las razones son humanitarias pues considera al malvado como un semejante.

7 M. SPANNEut, «La non-violence chez les Pères africaines avant Constantin» en Kyriakon. Festschrift Johannes Quasten (Münster, 1970) 36-39.

8 Lactancio, Divinae institutiones 6, 20, 8-10: «Si bien nos exhortaron elegantemente al desprecio de las cosas terrestres y nos animaron a la contemplación del cielo, no rechazan, sin embargo, esos espectáculos que se dan públicamente. Más bien, se divierten y asisten de buen grado a ellos; estos espectáculos, puesto que son grandes estímulos de vicios y sirven sobre todo para corromper las almas, deben ser erradicados por nosotros, ya que no solo no proporcionan nada en orden a la vida bienaventurada, sino que incluso la perjudican sobremanera. $\mathrm{Y}$ es que quien considera como un placer el ver cómo un hombre, aunque condenado merecidamente, es degollado, mancha su propia conciencia de la misma forma que si fuera espectador y partícipe de un homicidio cometido lejos de la vista de otros». 
que no hagamos incluso cosas que son lícitas entre los hombres. Así, el justo no deberá servir en la milicia, ya que su milicia es la propia justicia ${ }^{9}$; ni provocar una acusación capital contra nadie, ya que no hay diferencia entre matar a alguien con la espada y matarlo con la palabra: y es que lo que está prohibido es el crimen en sí, de forma que en este concepto divino no hay que hacer ninguna distinción: siempre será crimen matar a un hombre, del que Dios quiso que fuera un animal sagrado».

Dentro del catálogo de pecados que prohíbe el mandamiento «no matar», Lactancio incluye acusar a alguien de pena capital. El rechazo de la pena de muerte no es algo aislado sino que se encuentra en íntima relación con el rechazo de la participación en el ejército, en los espectáculos violentos y obscenos. El motivo principal radica en su concepción del hombre como un animal sacrosanctum, que se puede traducir como un ser sagrado e inviolable ${ }^{10}$. Por eso la pena de muerte para este autor además de ser siempre un crimen (semper nefas) es siempre un sacrilegio. Y para este Cicerón cristiano, como lo llamaban los humanistas del siglo XV y XVI, el sentido de la humanitas lo coloca en una posición enfrentada a la pena capital. Lo contrario sería canino modo vivere. La humanitas junto con la aequalitas y la innocentia son para él las grandes virtudes sociales. De él se dice que es el autor que describe mejor en el plano filosófico y sin invocar el Evangelio las actitudes que convienen al hombre en el seno de la comunidad humana ${ }^{11}$.

Sobre la posición de Lactancio conviene recordar el juicio negativo del patrólogo Quasten sobre su teología, que presenta postulados morales fundamentados más en la filosofía que en la religión ${ }^{12}$.

9 Uno de los manuscritos de las Divinae Institutiones agrega: «ni matar al ladrón» neque latronem interficere. La condena de la legítima defensa, que es tenida por lícita en la sociedad humana, aparece rechazada en este mismo libro sexto: 6, 18, 15-17.19.25.

10 Esta expresión sacrosanctum animal es un hapax en Lactancio; la elección de sacrosanctum seguido de nefas hace referencia al carácter inviolable de todo hombre. En Ovidio, Metamorfosis 1, 76 encontramos una expresión parecida sanctius his animal, que presenta al hombre como la culminación del cosmos según la filosofía estoica.

11 M. Spanneut, Tertullien et les premiers moralistes africains (Gembloux 1969) 189. Sobre la moral en Lactancio: 125-180.

12 J. Quasten, Patrología I (Madrid 1961) 678-679: «Aunque Lactancio fue el primer escritor latino que intentó una exposición sistemática de la fe cristiana, no es un teólogo auténtico. Para serlo le faltaban ciencia y capacidad. Incluso su obra principal, las Instituciones divinas, presenta el cristianismo simplemente como una especie de moral popular. Exalta con entusiasmo, es verdad, el martirio, el amor de 


\section{Argumentos biblicos}

Para argumentar con la Palabra de Dios se recurre a la interpretación de los textos bíblicos que iluminan esta problemática. El pasaje fundamental es el de $\mathrm{Rm} \mathrm{13,1-7} \mathrm{sobre} \mathrm{el} \mathrm{respeto} \mathrm{a} \mathrm{las} \mathrm{autoridades} \mathrm{civiles} \mathrm{y} \mathrm{de} \mathrm{modo}$ especial el versículo 4: el que tiene la autoridad es un servidor de Dios para tu bien. Pero, si obras el mal, teme, porque no en vano lleva la espada; porque es un servidor de Dios para hacer justicia y castigar al que obra el mal ${ }^{13}$. Vale la pena tener presentes para conocer el uso que hacían los Padres Jn 8, 1-11 Jesús y la adúltera, Mt 10, 34 no vine a traerpaz sino la espada, Mt 26, 52 guarda tu espada en la vaina, Lc 22, 36 vende la túnica y compra una espada, Mt 11, 12 el Reino de los cielos sufre violencia y los violentos lo arrebatan, Mt 22, 21 den al Cesar lo que es del Cesar y a Dios lo que es de Dios, Mt 13, 24-30.36-43 la parábola del trigo y la cizaña. El seguimiento de los comentarios a estos textos y las alusiones a ellos en la literatura patrística son de un valor fundamental, ya que el pensamiento cristiano en este período se encuentra en la exégesis patrística.

Ireneo de Lyon a fines del s. II, en polémica con los gnósticos, es el primero de los Padres en comentar el texto paulino de Rm 13. Afirma que los reinos de la tierra fueron establecidos por Dios y no por el demonio; para ello se apoya en la autoridad de san Pablo y explica: «Estén sujetos a las autoridades todas superiores, porque no hay autoridad que no venga de Dios. Y las que hay han sido ordenadas por Dios. Y de nuevo sobre las mismas: Porque no en vano lleva la espada; ministro como es de Dios, vengador para castigo del que obra mal. Y como prueba de que no habla de los poderes angélicos, ni de principados invisibles, como algunos se atreven a interpretar, sino de las autoridades humanas, añade: También por esto ustedes pagan los tributos, porque son ministros de Dios, encargados de cumplir este oficio» ${ }^{14}$.

Dios y del prójimo, las virtudes de humildad y castidad, pero apenas menciona el don sobrenatural de la gracia, que hace al ser humano capaz de vivir según este ideal. Habla de la transformación llevada a cabo por la nueva fe, pero sin prestar la suficiente atención a la redención de la humanidad por el divino Salvador. Sus postulados morales se fundamentan más en la filosofía que en la religión. Estaba, sin duda, profundamente convencido de la absoluta superioridad de la fe, pero es más hábil demoliendo el paganismo con la crítica que presentando el cristianismo en forma positiva. Jerónimo se dio perfecta cuenta de esto cuando exclamó: Utinam tam nostra confirmare potuisset quam facile aliena destruxit (Epist. 58,10). Si hay un pensamiento central que inspira toda la obra, es la idea de la divina Providencia, pues a ella vuelve incesantemente».

13 Cfr. también 1Pe 2, 13-17.

14 Ireneo, Adversus Haereses 5, 24, 1. 
Las sectas de los gnósticos y marcionitas condenaban o menospreciaban con razón todo acto de justicia por ir contra su sistema dualista; estos actos eran para ellos signos de las potestades arcónticas. Los marcionitas, por ejemplo, distinguían un Dios justo del Antiguo Testamento de la violencia y de la espada y un Dios bueno del amor y de la redención, Padre de Jesucristo revelado en el Nuevo Testamento. El Dios Bueno difícilmente podía aprobar el ejercicio de la autoridad militar y de los tribunales. Para Ireneo, en cambio, lo uno y lo otro entraban de lleno en la economía de Dios; siempre que hubiera alguna razón, no en vano ${ }^{15}$.

La justificación de la autoridad radica en la necesidad de poner freno a la violencia. Según Ireneo el pecado embruteció a los hombres y, para que no se devoren como peces unos a otros, Dios les impuso el temor a la autoridad humana. De esa manera se pudo conseguir alguna justicia, ya que el temor de Dios había desaparecido. Para este autor la falta de temor divino manifestado en el fratricidio de Caín hace necesario el ejercicio de la autoridad ${ }^{16}$.

Orígenes, por su parte, en su Comentario a la carta a los Romanos 9, 28 a propósito de $\mathrm{Rm}$ 13,1-4 dice:

15 A. Orbe, Teología de San Ireneo. Comentario al Libro V del "Adversus Haereses" II (Madrid 1987) 512.

16 Ireneo, $A d v$. Haer. 5, 24, 1-2: «Cuando el hombre se fue apartando de Dios, llegó a tal grado de embrutecimiento, que hasta su pariente le tuvo por enemigo y se movió sin temor en medio de sobresaltos y homicidios de toda clase. Y como no conocían temor de Dios, Él les impuso el temor del hombre, para que sujetos al poder de los hombres y amarrados por su ley lograran alguna justicia y se moderasen unos a otros, por temor a la espada que tenían ante los ojos, según dice el Apóstol: Porque no en vano lleva la espada, ministro como es de Dios, vengador para castigo del que obra mal (Rm 13, 4). De ahí también que los propios magistrados, al tener en las leyes un incentivo de justicia, de lo que obraren con justicia y según ley, no serán interrogados ni sufrirán castigo. Mas en cuantas cosas llevaren a cabo para ruina del justo inicua, ilegítima y tiránicamente, acabarán mal, ya que el justo juicio de Dios a todos llega por igual y sin desfallecimiento alguno. Según eso, el principado en la tierra fue instituido por Dios para utilidad de los paganos. No por el diablo, que jamás está en sosiego, ni consiente siquiera que los propios paganos vivan en paz. A fin de que por temor al principado de los hombres no se devoren, como peces, unos a otros, sino pongan freno mediante la institución de leyes a la multitud de injusticias de los gentiles. Y según esto, ministros son de Dios los que nos exigen tributos, atentos a este servicio $(\mathrm{Rm} 13,6) »$. 
«Pablo me sorprende en estas frases desde el momento que llama "ministro de Dios" a la autoridad civil y al juez terreno; y esto lo dice no una vez sola, sino que lo repite una segunda y una tercera vez».

Y continúa explicando que así como en Hch 15, 29 los apóstoles solamente mandaron abstenerse de algunas cosas para la sana relación de los cristianos provenientes del judaísmo y aquellos provenientes del paganismo, de los demás delitos no hablaron porque estaban bajo las leyes civiles y parecía superfluo que fueran prohibidos por una ley divina aquellas acciones que son castigadas suficientemente por la ley humana ${ }^{17}$.

Sin embargo, como hicieron los apologistas, Orígenes al comentar Rm 13, 2 realiza una distinción entre el origen divino del poder y su ejercicio concreto; de esa manera justifica la desobediencia a las leyes injustas que van contra la fe.

El Ambrosiaster, de modo semejante a Orígenes, se admiraba de que Pablo llamase a la autoridad «ministro de Dios». Comentando Rm 13, 1-6 llama al que manda vicario de Dios y portador de su imagen ${ }^{18}$. Sobre el versículo 4 dice:

«La autoridad es ministro de Dios para beneficio de quien obra el bien. Es claro que los jefes han sido puestos para que no se cumpla el mal. Sin embargo, si has hecho el mal teme, porque no sin motivo la autoridad lleva la espada. Esto es: por eso amenaza, para castigar si se descuida».

Sobre el pensamiento del obispo de Cesarea, devoto de Constantino, habría que decir que «la espada que para otros exégetas había que dejar solamente a Dios, en el caso de Eusebio es entregada por Dios mismo a un sujeto político histórico» ${ }^{19}$.

17 Orígenes, Com Rom 9, 28: “Todos los delitos que Dios quiere que sean castigados, ha querido que lo sean no por medio de los sacerdotes y de los jefes de las Iglesias, sino por medio del juez terreno. Y Pablo, conociendo bien este tema, llama justamente a éste 'ministro de Dios' y castigador de los delitos de quienes hacen el mal'.

18 El título imagen de Dios dado al princeps hará fortuna, lo encontraremos no solo en la Edad Media sino todavía en el siglo XIX. Cf. R. Deniel, «Omnis potestas a Deo. L'origine du pouvoir civil et sa rélation à l'Eglise», Recherches de Science Religieuse, 56 (1968) 49.

19 J. P. Martín, «El cristiano y la espada. Variaciones hermenéuticas en los primeros siglos», Revista Bíblica, 49 (1987) 41. 
Juan Crisóstomo en las homilías sobre la carta a los Romanos recuerda que san Pablo no hizo solamente un apelo al temor sino que recurrió a los razonamientos, por ejemplo, cuando mostró que el que obedece es recompensado por la autoridad. Explica que la institución de la autoridad no está ligada solamente al pecado, sino que hace a la concepción del or$\operatorname{den}^{20} \mathrm{y}$ no considera solamente el rol religioso y ético de la autoridad civil sino también su rol político como garante del bien común ${ }^{21}$ : «No es poca cosa lo que nos aporta para la vida presente, poniendo en movimiento las armas, rechazando a los enemigos, neutralizando a los sediciosos en las ciudades, resolviendo los procesos que nacen en toda ocasión $\rangle^{22}$.

\section{La represión de la herejia y del cisma}

Párrafo aparte relacionado con la pena de muerte merece el tema del poder político como ayuda para la Iglesia en el combate de la herejía. Después de Constantino la autoridad daba fuerza de ley a las decisiones conciliares que condenaban la heterodoxia colaborando con la deposición de los acusados de sus cargos eclesiásticos y en algunos casos enviando al exilio. Pero el empleo de la pena de muerte a alguien acusado de herejía resultó aplicada solamente una vez en el caso Prisciliano $(+385)^{23}$. Un asunto estrictamente eclesiástico referido a un obispo, censurado por gnóstico y maniqueo, se puso en manos del poder civil, se le dio tortura y se le aplicó la pena capital. El impacto de la condena y muerte de Prisciliano fue enorme. Martín de Tours se había hecho presente para evitar el derramamiento de sangre. Ambrosio de Milán manifestó su desacuerdo y hasta el propio Papa Siricio protestó ante el emperador. Hubo dos obispos delatores, los cuales fueron uno depuesto y otro exiliado.

Fuera de este caso se podría presentar a Optato, obispo de Milevi como partidario del uso de la fuerza para reprimir desórdenes provocados por

\footnotetext{
20 Juan Crisóstomo, Hom 23 in Ep ad Rom 2.

21 1Tim 2, 2: para que llevemos una vida tranquila.

22 Juan Crisóstomo, Hom 23 in Ep ad Rom 3.

23 K. Girardet, «Trier 385. Der Prozess gegen die Priszillianer», Chiron, 4 (1974) 577608; P. StockmeIER, «Das Schwert im Dienste der Kirche. Zur Hinrichtung Priszillians in Trien», en Festschrift für Alois Thomas (Trier 1967) 415-428; M.V. Escribano PAÑo, Iglesia y Estado en el certamen priscilianista. Causa Ecclesiae y iudicium publicum (Zaragoza 1988); «Haeretici iure damnati: el proceso de Tréveris contra los priscilianistas (385)» en Studia Ephemeridis Augustinianum, 46, Cristianesimo e specificità regionali nel Mediterraneo Latino (sec. IV-V) ( Roma 1994) 393-416.
} 
los donatistas. Vivió en África en el siglo IV y fue el único escritor católico que se empeñó literariamente en este asunto antes de Agustín. Tomó la defensa de los emisarios imperiales enviados para distribuir víveres durante un período de privaciones, quienes a su llegada fueron rechazados por la parte donatista y que durante una revuelta los soldados de los emisarios pasaron al filo de la espada a algunos revoltosos. Optato observa que a veces Dios permite que el mal sea castigado en este mundo explicando que: «Algunos males se realizan con un fin malo y otros males con un fin bueno. El bandido cumple sus malas acciones malvadamente; el juez su riguroso deber para un fin bueno cuando se hace vengador de la culpa perpetrada por el bandido»; indica como provenientes de un mismo Dios los mandamientos de «no matar» (Ex 20, 13; Deut 5, 17; Mt 5, 21) y de castigar con la pena de muerte algunas acciones (Deut 22, 22; Lev 20, 10). Seguidamente dice que los donatistas que fueron matados habían sido ellos mismos la causa de su muerte y que el funcionario imperial Macario actuó por la defensa de los derechos de Dios; del mismo modo Moisés, Pinjás y Elías habían aplicado la pena de muerte ${ }^{24}$. Al final de su obra retoma la defensa del legado imperial contra las acusaciones donatistas por haber sido acogido en la comunidad de la Iglesia. Reconoce que habría sido una culpa grave si el tal Macario hubiera actuado por propia voluntad aquello que tuvo que cumplir ${ }^{25}$. Esta fue la primera vez que un obispo católico defendió de manera decisiva la cooperación del Estado en cuestiones religiosas y su derecho al uso de la espada. También por primera vez se apeló al Antiguo Testamento para justificar estas acciones.

Agustín se vió también envuelto en la controversia donatista. A la luz de $\mathrm{Rm} 13$ ve en el poder un instrumento de Dios para reprimir el mal: «El temor de las penas, aun sin el deleite de la buena conciencia, al menos refrena el mal deseo dentro de los muros del pensamiento. Pero, ¿quién ha establecido esas leyes que reprimen vuestra audacia? ¿no son aquellos de quienes dice el Apóstol no llevan sin motivo la espada? Son realmente

\footnotetext{
24 Ортато, De schismate donatistarum 3, 5-7.

25 ОртАто, De schismate donatistarum 7, 6: «Resulta que él, según las palabras del Apóstol, fue un ejecutor de la voluntad de Dios, y entonces ¿qué motivo hay para sorprenderse, si hasta los jueces paganos merecieron ser reconocidos como ministros de la voluntad divina, como dice el Apóstol cuando afirma: No sin motivo el juez. lleva la espada? Él es ejecutor del querer de Dios. Y verdaderamente Macario en su función era juez».
} 
ministros de Dios que toman venganza del que obra mal» ${ }^{26}$. Sin embargo, se lo ve en las cartas 100, 133 y 134, entre otras, intercediendo por los criminales donatistas. Su postura sobre la represión de la herejía y sobre la pena de muerte ha sido ampliamente estudiada y es difícil de valorar ${ }^{27}$. A veces la cita de Rm 13, 4 parece un argumento ad hominem y no una prueba para demostrar la legitimidad de la pena capital. En este apartado y en el siguiente hacemos mención solamente de algunos ejemplos.

En la opinión de Hilario hay casos donde se usa legítimamente de la espada: «Por la sentencia del juez o por la necesidad de oponerse al ladrón» ${ }^{28}$, sin embargo, se opone enérgicamente al uso de la fuerza con exilios y cárceles en pro de la $\mathrm{fe}^{29}$.

Juan Crisóstomo, comentando la parábola del trigo y la cizaña, dice que Dios prohíbe la ejecución de los herejes porque el Señor se reserva el castigo, pero no condena la ayuda del brazo secular para reprimirlos, ni reducirlos a silencio, o para prohibir sus asambleas. Además manifiesta cierta esperanza en la conversión de los mismos ${ }^{30}$.

En el prólogo de la carta 15 de León Magno a Toribio obispo de Astorga se dice:

26 Contra litteras Petiliani II, 83, 184. Cf. Contra Epistulam Parmeniani I, 8, 13ss; C. litt. Pet I, 10, 16. Sobre Rm 13, 1-5 y la intervención del poder temporal en Agustín: cf. P. LANGA, «nota complementaria 23» en Escritos antidonatistas (Madrid 1990) 635-637.

27 Uno de los primeros estudios sobre el tema se debe al influyente filósofo y teólogo del s. XVII Hurtado de Mendoza. En el s. XX destacamos O. Schilding, Die Staats und Soziallebre des hl. Augustinus (Freiburg im Breisgau 1910); N. Noguer, «La doctrina político-social de San Agustín, especialmente sobre el castigo de los herejes», Razón y fe, 35 (1913) 349-355; G. Combès, La doctrine politique de Saint Augustin (Paris 1927); P.R.L. Brown, “Saint Augustine's Attitude to Religious Coercion”, Journal of Roman Studies, 54 (1964) 107-117; A. CocciA, «L'umanità di sant'Agostino. La pena di morte e la tortura», La Città di Vita, 17 (1962) 586-697. N. BlazQuez ha dedicado muchos estudios al tema: «El patrocinio agustiniano de la pena de muerte», Augustinus, 20 (1975) 253-296; «Pena de muerte y humanismo agustiniano», Augustinus, 21 (1976) 135-152; «Contexto ideológico y socio-jurídico de la pena de muerte, según san Agustín», Augustinus, 21 (1976) 303-369; «Textos agustinianos deprecativos contra la pena de muerte», Augustinus, 22 (1977) 59-86; «Textos polémico-interpretativos agustinianos sobre la pena de muerte», Augustinus, 22 (1977) 265-299.

28 Hilario de Poitiers, Com Mateo 32, 2.

29 Hilario de Poitiers, Contra Auxentium 4.

30 Juan Crisóstomo, Hom Mateo 46, 2. 
«Los príncipes de este mundo abominaron de esta sacrílega herejía (el priscilianismo) y proscribieron a su autor y a la mayor parte de sus discípulos con la autoridad de la ley imperial. [...] Sin embargo, esta disposición se prorrogó durante algún tiempo más, debido a la mansedumbre de la Iglesia que, aunque satisfecha por la sentencia sacerdotal, rehúye los castigos crueles, aun ayudándose de las severas disposiciones del príncipe de los cristianos. Los que temen el suplicio corporal, con frecuencia recurren a un remedio espiritual».

Por un lado el texto muestra su postura contraria a «los castigos crueles» y por otro reconoce la ayuda que presta el poder político mediante «severas disposiciones». De todos modos para que no se expandiese otra herejía que ocupó gran parte de sus preocupaciones, el monofisismo, dirigió un llamado al poder civil para que interviniera en cuestiones eclesiásticas. De lo que sí estamos seguros es que el pedido no fue para aplicar la pena capital ${ }^{31}$.

\section{El respeto a la Ley y el ejercicio de la misericordia}

Ambrosio de Milán tiene una significativa visión frente a la pena capital ${ }^{32}$. Como otros Padres de la Iglesia, reconoce la institución divina de la autoridad terrena. En el cometario al Evangelio de Lucas dice: «No es malo el poder sino la ambición. Por lo demás la institución de la autoridad viene de tal forma de Dios, que el que usa bien de ella se convierte en ministro de Dios: Es ministro de Dios para el bien $(\mathrm{Rm} 13,4)$. No hay culpa alguna en el ministerio sino en el ministro» ${ }^{33}$.

Hay también en este autor una preferencia por la misericordia y la benevolencia ante el mal que se sufre. En una obra destinada a los clérigos invita a excluir la legítima defensa y pone para ellos el modelo de Cristo, el

31 LeÓn Magno, Ep 156, 3.

32 M. Sordi, «La lettera di Ambrogio a Studio e il problema della pena di morte» en Polyanthema. Studi di letteratura latina offerti a Salvatore Costanza (Messina 1989) 275-283. M. SORDI, «Pena di morte e "braccio secolare" nel pensiero di Ambrogio» en Metodologie della ricerca sulla tarda anticichità (Atti del primo convegno dell'Associazione di studi tardoantichi; Napoli 1987), a cura di A. Garzya, Napoli 1989, 179-187. Ambos artículos están reeditados en M. Sordi, «Sant'Ambrogio e la Tradizione di Roma», Studia Ephemeridis Augustinianum, 111, 2008) 85-91; 93-101.

33 Ambrosio, Expositio Evangelii secundum Lucam 4, 29. Unos renglones más adelante 4, 31 recuerda: «La autoridad no viene del diablo pero está expuesta a las insidias del diablo. No se sigue, por lo mismo, que la institución de la autoridad sea mala, porque esté expuesta al mal». 
cual «no quiso que hiriesen a sus perseguidores para que lo defendieran»; ejemplifica con Mt 26, 52: guarda tu espada en la vaina ${ }^{34}$.

Cuando fue interrogado por un magistrado sobre su postura acerca de la pena capital presentó el ejemplo de Cristo que se encuentra con la mujer adúltera en Jn 8, 1-11 como modelo a seguir (babes quod sequaris). La actitud de Jesús, que no trata la cuestión de la culpabilidad de la mujer ni la conveniencia del mandato mosaico de lapidarla, invita a sus apasionados acusadores a examinar la propia inocencia antes de aplicar la pena establecida. A la luz de la propia culpa el celo por apedrear a la adúltera se desvanece. La respuesta de Ambrosio al magistrado llamado Studio se halla en la carta $50^{35}$. Es un texto fundamental sobre la licitud de un juez cristiano para dictar la sentencia capital. En ella el santo obispo demuestra gran equilibrio teniendo en cuenta por un lado la exigencia de la misericordia y por otro lado la autoridad de san Pablo en Rm 13, 4, que legitima el uso de la espada. La autoridad del Apóstol y la tradición de la Iglesia garantizan la licitud de la pena capital para los delitos más graves ${ }^{36}$. Además, el obispo de Milán teme que la negación de la legalidad provoque el furor de los delincuentes (Ep 50, 9). Sin embargo, califica dignos de alabanza a los magistrados que después de haber declarado este tipo de pena se privan voluntariamente por un tiempo de la comunión ${ }^{37}$. Excusa si se aplica la sentencia de muerte pero felicita a los magistrados que se abstienen de dictarla (Ep 50, 3: excusationem habebis si feceris, laudem si non

34 Ambrosio, De officiis ministrorum 3, 4.

35 Utilizamos la numeración de FALLER (CSEL).

36 Ambrosio señala que hay algunos que excluyen de la comunión a quienes dictan este tipo de sentencias (Ep 50,2). Podría tratarse del grupo cismático de los novacianos. Poco tiempo después de la muerte de Ambrosio, el papa InOCEnCIO I se remite también a la Tradición cuando en el año 405 ante una pregunta de Exuperio obispo de Tolosa sobre la sentencia a la pena capital por parte de un magistrado cristiano responde en la epístola VI Consulenti tibi 3, 7-8: «En cuanto a esta pregunta no tenemos nada en definitivo de aquellos que nos han precedido. Debe ser recordado que el poder fue concedido por Dios, y la espada fue permitida para vengar el crimen; el que realiza esta venganza es el ministro de Dios. ¿Qué motivos tenemos nosotros para condenar una práctica que todos sostienen es permitida por Dios? Mantenemos, por lo tanto, lo que se ha observado hasta ahora, para no alterar la disciplina y aparecer como estar obrando contra la autoridad de Dios».

37 Un siglo antes de Ambrosio, Cipriano, en De bono patientia 14, señalaba la coherencia eucarística refiriéndose no a la pena de muerte sino al homicidio cuando decía «después de haber tomado la Eucaristía la mano no debe ser manchada con la sangre de la espada». 
feceris). En la carta 68 al mismo magistrado retoma la cuestión de la celebris absolutio de la mujer adúltera con motivo de la acusasión de Prisciliano por parte de algunos obispos, a quienes comparó con los judíos que acusaron a la mujer (Ep 68, 2-3).

Algo semejante se encuentra en la obra antedicha dedicada a las virtudes del clero, cuando enumera dentro de los actos dignos de honra para un sacerdote salvar de la pena capital a un condenado; pero a la vez indica que el motivo debe ser la misericordia y no el desafío del poder legítimo (ne videamur iactantiae magis causa facere, quam misericordiae), ya que de esa manera se perturbaría el orden y se podrían ocasionar graves daños ${ }^{38}$. Marta Sordi, estudiosa del cristianismo en época imperial, retiene muy importante el rechazo de toda iactantia frente al Estado en el pensamiento de un obispo que, como Ambrosio, ha sido frecuentemente acusado de haber humillado la autoridad del Estado ${ }^{39}$. Este rechazo es firme en el obispo de Milán también en tiempos de la carta al emperador Teodosio por la matanza de Tesalónica en el 390 (Ep 11 extra coll.), ya que la culpa por la cual pide hacer penitencia al emperador no está en haber matado a culpables sino a inocentes. En efecto, para él perdonar a los culpables es clementia, aunque matarlos puede ser aequitas, pero matar a los inocentes homicidium est ${ }^{40}$. El término aequitas, explica Sordi, al igual que ius tiene particular referencia a los actos realizados por la autoridad en el ejercicio de su poder legítimo ${ }^{41}$.

Agustín sigue la misma línea de Ambrosio. En la carta 153, respondiendo a la consulta del funcionario de la 'diócesis' civil de África sobre la intercesión de los obispos en favor de los reos, utiliza Jn $8,7^{42}$, el que esté sin pecado tire la primera piedra, para decir que «de ese modo Cristo no recusó la ley, que mandó matar a los culpables; pero, aterrándolos a ellos,

\footnotetext{
38 Ambrosio, De Officiis ministrorum 2, 21.

39 M. SorDI, «Sant'Ambrogio e la Tradizione di Roma» 97-98.

40 La autoridad del Estado que la Iglesia había reconocido al imperio pagano la reconoce también Ambrosio al imperio cristiano. En la carta 58, 1 llama a las cosas por su nombre hostem ferire victoria est, reum aequitas, innocentem homicidium.

41 M. SORDI, «Sant'Ambrogio e la Tradizione di Roma» 90.96.

42 Jn 8, 1-11 ha sido meditado y comentado por Agustín en muchos sermones y en In Ioh Tract 33. Es sabido que la perícopa difícilmente entró en el canon de los evangelios antes del s. III. El mismo Agustín nos dice que suscitó oposiciones y que algunos «arrancaron de sus códices aquella escena en que el Señor perdonó a la adúltera». Cf. De coningiis adulterins II, 7, 6 .
} 
los invitó a la misericordia» $(153,4,9)$ y $\mathrm{Rm} 13,1-8$ escribiendo que «estas palabras del Apóstol muestran la utilidad de vuestra severidad» y agrega «nada se hará cruelmente, nada inhumanamente. Así se temerá el castigo del juez, de modo que no se desdeñe la piedad del que intercede» (153, 6, 19). Para él «no se ha instituido en vano la potestad regia, el derecho de vida y muerte del juez. [...] La intercesión de los obispos no se opone a esta ordenación de las cosas humanas» $(153,6,16)^{43}$.

\section{Conclusión}

En los diversos escritores cristianos de los cinco primeros siglos se nota consenso en reconocer el origen divino de la autoridad civil y por lo tanto para obedecer las leyes justas. Fuera de las aplicaciones injustas, la justificación del sistema penal radica en la necesidad de poner freno a la violencia. Según Ireneo, la existencia del pecado hizo necesario el ejercicio de la autoridad punitiva. Para el Crisóstomo esta institución no sólo está ligada al pecado sino que hace a la concepción del orden.

Sobre la pena capital hay diversas opiniones: desde la justificación a través de la imagen médica de la amputación de una parte infectada en beneficio de todo el cuerpo social como en el caso de Clemente Alejandrino, hasta el rechazo total como en el caso del Lactancio. En el medio podríamos ubicar la enseñanza de Ambrosio que reconoce a la autoridad la posibilidad de dictar la máxima sanción a la vez que exhorta a la clemencia. Llama la atención que las dos puntos de vista extremos justifiquen sus posiciones racionalmente y no desde la Sagrada Escritura. Clemente desde la imagen terapéutica utilizada ya por Platón y Lactancio con fundamentos humanitarios esgrimidos por los estoicos.

Sobre la pena de muerte aplicada a los acusados de herejía, la ejecución de Prisciliano fue el único caso en este período que impactó negativamente. Otros autores partidarios de la ayuda del poder secular en la lucha contra las herejías se mostraron contrarios a la aplicación de la pena capital.

43 En De Civitate Dei I, 21 dice que dentro de las excepciones al mandamiento «no matarás» señaladas por la autoridad divina «los que investidos de pública potestad, y ateniéndose a su ley, es decir, el dominio de la razón más justa, han dado muerte a reos de crímenes». Sin embargo, en los sermones exhorta al temor por las propias culpas y al ejercicio de la misericordia según el ejemplo del Señor con la mujer adúltera. Cf. Serm. 13, 4-7; 16A, 4. 
Ambrosio demuestra gran sabiduría para responder con la Palabra de Dios consignada en la Escritura e interpretada por la Iglesia a las consultas de los magistrados cristianos que piden orientación para la acción civil. El obispo de Milán sabe conjugar la autoridad apostólica de Rm 13, 4 con la misericordia manifestada por Jesús ante la mujer adúltera de Jn 8 , 1-11; fue el primer autor en utilizar este pasaje evangélico y utilizarlo en esta cuestión de la pena de muerte. Esta línea será retomada por Agustín a quien también se dirigirán los magistrados con planteos similares. 
Resumen: Este artículo estudia el tema de la obediencia a las autoridades civiles por parte del pensamiento cristiano de los primeros cinco siglos. Asimismo se considera el tema de la pena de muerte, la cual tendrá una valoración variada entre los autores patrísticos. Se constata que las opiniones extremas, a este respecto, no esgrimen una fundamentación bíblica, sino racional.

Palabras clave: Pena de muerte, patrística, autoridad civil.

Abstract: This article examines the theme of obedience to the civil authorities on the part of Christian thought of the first five centuries. It also considers the issue of the death penalty, which receives a varying appreciation among the patristic authors. It is stated that, in this respect, the extreme opinions do not use a biblical foundation, but a rational one.

Key words: Death penalty, patristics, civil authority. 